\title{
Experimental and numerical study of pseudo-2D circulating fluidized beds
}

\author{
Adam Klimanek $^{\mathrm{a}} *$, Wojciech Adamczyk $^{\mathrm{a}}$, Sirpa Kallio ${ }^{\mathrm{b}}$, Paweł Kozołub ${ }^{\mathrm{c}}$, Gabriel Węcel ${ }^{\mathrm{a}}$, \\ Andrzej Szlęk ${ }^{\mathrm{a}}$ \\ ${ }^{a}$ Institute of Thermal Technology, Silesian University of Technology, Konarskiego 22, 44-100 Gliwice, Poland \\ ${ }^{b}$ VTT Technical Research Centre of Finland Ltd, P.O. Box 1000, FI-02044 VTT, Finland \\ cAmec Foster Wheeler, Staszica 31, 41-200 Sosnowiec, Poland \\ *Corresponding author. Tel: +48 32 2372974; Fax: +48 32 2372872; E-mail: adam.klimanek@polsl.pl
}

\begin{abstract}
We present experimental investigations and numerical simulations of apseudo-2D riser. Experiments were performed for various airflow rates, particle types/diameters, and particle size distributions. Pressure distributions along the wall of the riser were measured. Additional measurements from a smaller pseudo-2D riser (Kallio et al., 2009; Shah et al., 2012) were used to analyze horizontal solids volume fraction profiles. The experimental data were compared with simulation results carried out using an Euler-Euler approach. A mesh sensitivity study was conducted for numerical simulations and effects associated with simplifying real 3D geometry to a 2D model were examined. In addition, the effect of using an algebraic equation to represent the granular temperature versus a full partial differential equation also was examined for numerical simulations. Results showed small but significant near-wall sensitivity of the flow variables to mesh size. Substantial differences in mean pressure, solids distribution, and solid velocities were obtained, when 2D and 3D simulation results were compared. Finally, applying the simplified granular temperature equation for turbulent fluidization and for dilute-phase transport can lead to incorrect predictions in models.
\end{abstract}

Keywords Circulating fluidized bed; Euler-Euler approach; Gas-solid flow; Kinetic theory of granular flow; Particle size distribution; 2D vs 3D

\section{Introduction}

Circulating fluidized beds (CFB) are frequently used as chemical reactors for combustion, gasification, and heterogeneously catalyzed synthesis and cracking. Understanding and appropriately modeling CFB hydrodynamicsis vital for predicting their transport processes, i.e., heat and mass transfer, as well as chemical reactions occurring in these reactors. This knowledge is used in multiphase flow research, and for proper design and optimization of industrial facilities. A variety of methods have been developed and used to model such hydrodynamics, using various solvers for computational fluid dynamics. These approaches can be subdivided, based on the spatial and temporal scales accounted for in the models (Myöhänen \& Hyppänen, 2011). They can 
also be distinguished based on the way the solid phase is treated. Lagrangian or discrete particle (or phase) models track the particles or their groups (clouds). In Eulerian or two-fluid models, the solid phase is treated as continuous. Here, the particle motion is averaged out, which allows simulations to be performed on meshes much coarser than the particle diameters involved. Such models can be applied to large-scale system simulations. However, this infers that closure approximations must be provided for both fluid-solid and solidsolid interactions. Fluid-solid interactions are realized using drag coefficients (Gidaspow, 1994). For solidsolid interactions, the kinetic theory of granular flow (KTGF) (Lun, Savage, Jeffrey, \& Chepurniy, 1984; Gidaspow, 1994) is applied, which allows the user to determine solid stresses arising from particle streaming and collisions. In dense regions, however, frictional stresses become important and additional closures must be provided to account for these phenomena. Thus, in Eulerian models, the solid phase is represented by its volume fraction, density, and velocity. Furthermore, solid pressure, bulk, frictional and shear viscosities, as well as a single representative diameter of the particles are assigned to the solid phase. In real systems, however, we usually deal with polydisperse particles. An Eulerian approach is frequently applied to gas-solid flow and specifically to CFB modeling for both small scale facilities (Kallio et al., 2009; Hartge, Ratschow, Wischnewski, \& Werther, 2009; Wang et al., 2010; Almuttahar \& Taghipour, 2008a, 2008b; Cloete, Amini, \& Johansen, 2011; Chalermsinsuwan, Piumsomboon, \& Gidaspow, 2009a, 2009b; Lu et al., 2008; Zhang, Lu, Wang, \& Li, 2008) and large industrial systems (Wischnewski, Ratschow, Hartge, \& Werther, 2010; Zhang, Lu, Wang, \& Li, 2010).

Here, we present application of the Eulerian approach to modeling of apseudo-2D CFB with Geldart B and D particles. First, we present our experimental study, followed by simulations of this same set up, which are used to compare with experimental data obtained from twopseudo-2D CFBs. One of the CFBs is installed at the Silesian University of Technology (SUT) in Poland, and the other at the Åbo Akademi University in Finland. Results of the experiments and simulations carried out at the second facility are from the literature (Kallio et al., 2009; Shah, Ritvanen, Hyppänen, \& Kallio, 2012). In this research, the effect of particle size and particle size distribution on the quality of results is examined. This was evaluated through comparison of simulations and experimental results of particle groups in three sizes. In our simulations, the Eulerian solid phase was characterized by a single Sauter mean diameter.

In the two-fluid model, solid-solid interactions are determined using the KTGF. This requires solution of the balance equation for granular temperature. A full partial differential equation, or its simplified form (an algebraic equation), is solved to obtain granular temperature and the solid stress tensor. The partial differential equation is complex and difficult to solve, while the simplifications introduced in the algebraic equation are only valid for higher solid volume fractions and relatively low solid velocities (van Wachem, Schouten, Krishna, \& van den Bleek, 1998; van Wachem, Schouten, van den Bleek, Krishna, \& Sinclair, 2001). Such conditions occur in bubbling fluidized beds. However, because of its simplicity and stable behavior during 
calculations, the algebraic equation is frequently used in both bubbling fluidized beds (van Wachem et al., 1998; Cloete et al., 2013) and risers (Cabezas-Gomez, Silva, \& Milioli, 2006). Here, we evaluate the effect of using the algebraic versus the partial differential equation for solving turbulent fluidization.

Because of the tremendous computational resources required to perform simulations using 3D models, in many studies (Cloete et al., 2011; Benyahia, Arastoopour, Knowlton, \& Massah, 2000; Almuttahar \& Taghipour, 2008a, 2008b), as well as in this research, the geometries are reduced to 2D, or else the simulations are performed on coarse meshes. The effect of using 2D versus 3D computational models for a bubbling, slagging, and turbulent fluidized bed was examined in detail by Xie, Battaglia, and Pannala (2008). They concluded that the difference between their results became more pronounced, as fluidization velocity increased. Therefore, such effects are expected to influence modeling of risers. Cloete et al. (2013) presented the influence of representing a pseudo-2D facility operated in a bubbling regime by 2D and 3D geometry. They concluded that the neglected friction at the walls in the 2D simulation considerably affected the flow field. To separate out the effects of neglecting thickness in the pseudo-2D facilities at higher superficial velocities, a 3D simulation was performed for one of our cases, using the same mesh in the XY plane as the 2D mesh. The influence of neglecting the third dimension in this model is examined in the last section of this paper.

\section{Experimental}

The experimental facility at the SUT is shown in Fig. 1. The CFB is a $3.0-\mathrm{m}$ high and $0.6-\mathrm{m}$ wide pseudo-2D riser, with depth of $17 \mathrm{~mm}$. The equipment consists of a blower, flowmeter, air distributor, riser, a solids separator (settling chamber), and a return leg with a loop seal. The air is supplied through 13 nozzles situated at the bottom of the riser. The fluidized solids, which leave the riser, are separated in the settling chamber, and returned back to the riser via a recirculation leg, with a fluidized loop seal. Measurements were conducted for different gas velocities. Gas pressure distribution along the right wall of the riser was measured. The pressure sensors were unevenly spaced at various heights, i.e., at 0.1, 0.3, 0.4, 0.6, 0.9, 1.65, and $2.35 \mathrm{~m}$, measured from the bottom of the riser. The measured pressures were the only quantities compared with our simulation results. All other measurements served as boundary conditions for the numerical model.

Fig. 1

The experiments were conducted with glass particles, belonging to Geldart B and D groups. For clarity, the particles were grouped into three types, because they consisted of slightly different glass materials or were characterized by different size distributions. The properties of these different particle types are presented in Table 1. The maximum solid volume fraction (packing limit) was measured by means of the gas expansion method (Dullien, 1992). Type 3 particles were assumed to be monosized, while size distributions for type 1 and 2 particles were measured. Results of these sieve analyses are presented in Fig. 2. 
Fig. 2 \& Table 1

Three experimental series were conducted with various particle types. In the first experiment, particles of type 1 , with a Sauter mean diameter of $d_{32}=281 \mu \mathrm{m}$ were used. In the second experiment, type 2 particles with a Sauter mean diameter of $d_{32}=548 \mu \mathrm{m}$ were fluidized; while in the third experiment, a mixture of type 2 and type 3 particles was fluidized. This mixture was composed of 50\% type 2 and 50\% type 3 particles by mass, giving a Sauter mean diameter of $d_{32}=708 \mu \mathrm{m}$. Table 2 summarizes the particle types used in each experiment, giving their Sauter mean diameters and corresponding terminal velocities in air (at $T=298 \mathrm{~K}$ and $p=1 \mathrm{~atm}$ ).

Table 2

In each experiment, pressure distributions were determined for four fluidization velocities. The various cases studied are distinguished by case number, yielding cases 1 to 12 . In Table 3, a summary of the fluidization velocities and air densities is given for each case. Generally, densities were determined from pressure and temperature measured at the bottom of the test facility, above the air inlet nozzles.

\section{Table 3}

In each experiment, a total mass of $5 \mathrm{~kg}$ of solids was fluidized. During operation of the facility, part of the solid particles was accumulated in the recirculation system. This accumulated mass was controlled by air flow in the syphon-like loop seal, which allowed us to keep almost constant mass in the riser. However, this was difficult for cases 1-4 in which small particles with broad size distribution were fluidized. The mass of particles in the recirculation section of the CFB was measured by suddenly shutting off the air flow. Measurements showed that approximately $0.4 \mathrm{~kg}$ of particles were accumulated in the recirculation part for cases 5-12, resulting in $4.6 \mathrm{~kg}$ present in the fluidization chamber for these cases. In cases 1-4, the measured mass in the recirculation system varied considerably, giving masses of $0.2 \mathrm{~kg}$ for case $1,0.5 \mathrm{~kg}$ for case 2, 0.75 $\mathrm{kg}$ for case 3, and $1.2 \mathrm{~kg}$ for case 4.

Because the only measured parameter in this study was pressure along the riser height, the data presented in earlier works (Kallio et al., 2009; Shah et al., 2012) were also used to verify the predictions of our numerical simulations; in these earlier studies both the pressure and volume fraction distributions were measured in a similar pseudo-2D facility. The experimental facility used in the original study (Kallio et al., 2009) was $3 \mathrm{~m}$ high, $0.4 \mathrm{~m}$ wide, and its depth was $0.015 \mathrm{~m}$. Glass beads with a Sauter mean diameter of $0.385 \mathrm{~mm}$ were fluidized. Two cases were considered in these earlier experiments, herein after case 13 and case 14. In case 13, the fluidization velocity was $3.1 \mathrm{~m} / \mathrm{s}$ and the mass of solids in the riser was $2.76 \mathrm{~kg}$; whereas for case 14 , the velocity was $3.5 \mathrm{~m} / \mathrm{s}$ and the mass was $2.5 \mathrm{~kg}$. The density of the glass particles was $2480 \mathrm{~kg} / \mathrm{m}^{3}$ (Kallio et al., 2009). 


\section{Numerical simulations}

\subsection{Geometry and mesh generation}

Geometry of the numerical model was simplified to minimize the computational effort of the simulation, while preserving the important features of the facility. Therefore, the model only encompasses the riser section and part of the return leg, as shown in Fig. 3. Moreover, the pseudo-2D experimental facility was treated as a 2D geometry in our simulations.

Fig. 3

A quadrilateral mesh was created, with square elements in the riser section. The base mesh was built out of 6×6- $\mathrm{mm}^{2}$ squares, giving a total of 50,988 elements (including the recirculation leg). The base mesh spacing was selected to be smaller than the finest mesh examined in Kallio et al. (2009) and Shah et al. (2012), which was shown to predict well the mesoscale structures, and to be coincident with experimental data for the 0.385mm diameter particles. Thus, the selected mesh in this study was 21 times larger than the smallest particle diameter (particle type 1$)$. A mesh sensitivity study also was carried out, in which both finer $(1.5 \times 1.5$ - and $3 \times 3$ $\left.\mathrm{mm}^{2}\right)$ and coarser $\left(12 \times 12-\mathrm{mm}^{2}\right)$ meshes were used. Mesh sensitivity will be discussed later.

\subsection{Governing equations}

The Eulerian model equations and the various closures implemented in ANSYS Fluent code (ANSYS Inc., PA, USA) are described in detail in its software documentation (ANSYS Inc., 2011) and have been widely described in the literature (Almuttahar \& Taghipour, 2008a; Shah et al., 2012; Cloete et al., 2011). The submodels used in this study are listed in Table 4, with a reference for each model. The closure models and parameters used in our simulations (unless otherwise specified) also are presented in Table 4. Our simulations were performed using the standard $k-\varepsilon$ model, with a dispersed option (ANSYS Inc., 2011), which is applicable for the dilute secondary phases. This was assumed to be true in our study although dilute and dense regions in the riser coexist in most of the analyzed cases.

Table 4

\subsection{Boundary conditions}

The types of boundary conditions used in our simulations are shown in Fig. 3. In our experiments, air was supplied at the bottom of the riser ( $0.6 \mathrm{~m}$ wide) through 13 nozzles. In the model, the geometry of the nozzles and flow non-uniformity at the air inlet were neglected. The air was treated as incompressible (having constant 
density), and the air velocities at the air inlet were set to constant values, corresponding to the measured superficial gas velocities. These conditions infer a constant air mass flow rate. The solid phase velocity and volume fraction were set to zero at this boundary. Kallio, Peltola, and Niemi (2014) showed that although the bed behavior in the bubbling regime depends on the details of the air inlet nozzle geometry, in turbulent and fast fluidization regimes, the results are not sensitive to the simplifications made for the air distributor geometry, when the spacing between orifices in a pseudo-2D unit is the same as in the present study. We assumed that constant pressure equal to the ambient air pressure occurred at the top boundary (both phases). A no-slip wall boundary condition was set for the gas phase, while the Johnson and Jackson (1987) boundary condition was used for the solid phase at all walls. The corresponding constants for these boundary conditions were assigned, unless specified differently in Table 4. The particles leaving the riser at the top were recirculated back through the 0.2-m wide return leg, as shown in Fig. 3. This was implemented by means of a user-defined function within the ANSYS Fluent code; it was used to calculate the recirculating solid phase velocity. The gas phase velocity was set to zero at the recirculation inlet. This procedure preserved constant mass of particles within the riser, as for the experiments. In the simulations, the solid phase was characterized by a single Sauter mean diameter $d_{32}$, as given in Table 2 .

\subsection{Solver settings}

The phase-coupled SIMPLE solver was used for our calculations. A second order discretization scheme was used for the momentum equation, while a first order one was used for the granular temperature, turbulent kinetic energy, and its dissipation. The QUICK scheme was used for the continuity equation, and a first order implicit scheme was used for time discretization.

\subsection{Data sampling and time averaging}

The unsteady simulations were run with a constant time step of $0.5 \mathrm{~ms}$. The solution was initialized with a constant mass of the solid phase in the riser. Data sampling for determining the time averages was begun $10 \mathrm{~s}$ after starting the simulation. During this initial period, a pseudo-steady state was obtained, while by the end of this period, the flow variables oscillated about distinct average values. The data contributing to these averages were collected at each time step (frequency of $2000 \mathrm{~Hz}$ ) for $20 \mathrm{~s}$.

\section{Results and discussion}

\subsection{Comparison with experiments}

The quantities determined from laboratory experiments, and used as boundary conditions in subsequent simulations (cases) are provided in Table 3. Because the air velocity was set at the air inlet boundary, the air 
mass flow rate for each case also is given in Table 3. Likewise, the total mass of the solids was constant for each case, such that in cases 5-12 the mass in the riser was equal to $4.6 \mathrm{~kg}$. Given that the 2D geometry is $1 \mathrm{~m}$ deep, this corresponds to $270.59 \mathrm{~kg}$ of solid phase in the 2D CFD model. For cases 1-4, the masses in the riser were 4.8, 4.5, 4.25, and $3.8 \mathrm{~kg}$, respectively, corresponding to 282.35, 264.71, 250.0, and $223.53 \mathrm{~kg}$ of solid phase in the 2D CFD model. In Fig. 4, the mean pressure distributions along the right wall, and mean volume fractions in the middle of the riser are presented. The pressure distributions obtained from simulations are compared with these experimental data.

\section{Fig. 4}

In all simulated cases, the pressure distributions do not perfectly match the measured profiles. The measured and computed pressures only coincide at $0.1 \mathrm{~m}$ above the air inlet. For cases 5-12, the profiles also match in the upper regions of the riser. However, in the intermediate regions, substantial differences occur for all cases. For larger particles (cases 5-12), the pressure predicted by the model is generally higher than the measured one. This seems to be independent of the addition of large $(1 \mathrm{~mm})$ monosized particles. For cases 14, the trends are slightly different. The pressure is predicted well at the very bottom of the riser, but it is underestimated in the upper regions. In the intermediate regions, the behavior depends on the fluidization velocity. For the region 0.1-0.6 m above the air inlet, the pressure is overestimated, except in case 4 with the highest velocity, for which the pressure is predicted reasonably well. The largest discrepancy in this region occurred for case 1 , where the difference between predicted and measured pressure exceeded $100 \%$ of the measured values.

The effect of particle size and particle size distribution can be deduced from the pressure and volume fraction profiles. In cases 5-8, particles of type 2 were used, with a particle size distribution that was very narrow, such that the particles can be viewed as being monosized (with a Sauter mean diameter $d_{32}=548 \mu \mathrm{m}$ ). Fig. 4(b) shows that the pressures are always higher for faster velocity. In addition, the profiles for the two smaller fluidization velocities (cases 5 and 6) and two higher velocities (cases 7 and 8) were closer to each other. Through examining the data in Table 2 and Table 3, this behavior can be attributed to the terminal velocity for the Sauter mean diameter, which is higher than the fluidization velocities in cases 5 and 6 , but smaller for cases 7 and 8. Such differences were not observed in the experimental data, where a smooth transition with increasing fluidization velocity took place. In cases 1-4, the particle size distribution is broad, with approximately $45 \%$ of the particles (by mass) having smaller diameter than the Sauter mean value, and 55\% having a larger diameter. Fig. 4(a) illustrates that for cases 1-4, the pressure at $0.1 \mathrm{~m}$ above the inlet decreases with increasing fluidization velocity. As the velocity increases, more particles were carried away to the upper regions, redistributing the pressure. This effect is also associated with the decrease of total mass of particles within the riser observed in cases 1 to 4 . For case 1 , the fluidization velocity was smaller than the 
terminal velocity for the Sauter mean diameter, while for cases $2-4$ it was higher (Tables $2 \& 3$ ). This is apparent in both experimental and simulated pressures and volume fraction profiles because cases 2-4 have results that are grouped closer together. For all cases 1-4, the fluidization velocities are higher than the terminal velocity for the smallest diameter particles, and smaller than the terminal velocity for the largest diameter. In cases 9-12, a mixture of particle types 2 and 3 was used (50/50 by mass). The terminal velocity for the Sauter mean diameter of type 2 particles was higher than the fluidization velocities in case 9, almost equal to it for case 10, but smaller for cases 11-12. In contrast, the terminal velocity for the Sauter mean diameter of type 3 particles was higher than the fluidization velocities in cases 9-11. These properties are apparent in the pressure and solid volume fraction profiles shown in Fig. 4(c). For case 9, the solid volume fraction and static pressure are zero above $1.75 \mathrm{~m}$, while substantial amounts of solids were observed in the entire riser for cases 10-12. The effects of a broad size distribution in cases 1-4 and 9-12 are noticeable, manifesting as large pressure drops occurring between the air inlet and a 0.5-m height for small fluidization velocities. These effects are caused by larger particles residing at the bottom of the riser.

To verify our computational strategy, additional calculations were carried out and compared with experimental and simulation results obtained from the literature (Kallio et al., 2009; Shah et al., 2012). Differences between the calculations performed in this study and those presented in Kallio et al. (2009) are:

- Our mesh was built out of $5 \times 5-\mathrm{mm}^{2}$ squares giving a total number of 48,800 elements, while the original mesh spacing in Kallio et al. (2009) was $6.25 \mathrm{~mm}$.

- Granular viscosity in our study was calculated according to the Gidaspow model (Gidaspow, Bezburuah, \& Ding, 1992), whereas Kallio et al. (2009) used a Syamlal-O’Brien model (Syamlal \& O’Brien, 1989).

- $\quad$ Our time step was $0.5 \mathrm{~ms}$, whereas in Kallio et al. (2009) it was $0.2 \mathrm{~ms}$.

The wall specularity coefficient (0.001) was the same as in Kallio et al. (2009). The simulations were run as unsteady for10 s to obtain quasi-steady state, and then for another $10 \mathrm{~s}$ for collecting time averaged data. In Fig. 5, pressure distributions along the right wall of the riser for cases 13 and 14 are presented. Clearly, in both cases the predicted pressure profiles are very similar. The profile agrees well with measurements for case 13 , whereas the pressure is substantially underestimated in case 14. Given their coincident volume fraction profiles, we suspect that the measured pressure profile in case 14 is not accurate. This generates a similar situation to that described for cases 1-4, where for higher superficial air velocities the pressure drop was underestimated by the model. Although the computed and measured pressure profiles do not coincide for case 14, this appears to have little influence on the predicted solid volume fraction distributions. In Fig. 6, the profiles of solid volume fraction along the bed width at 0.2 - and 1.3-m height above the air distributor are presented. Clearly, the 
models predict the distributions reasonably well. The asymmetry of the profiles and higher volume fractions on the left side of the system reflect the presence of the recirculation inlet in this region.

Figs. $5 \& 6$

In the experiments conducted at SUT, the mass loading of solids was almost the same as in case 13, while the loading in case 14 was slightly lower. The total mass of particles with respect to volume of the riser amounted to $150.3 \mathrm{~kg} / \mathrm{m}^{3}$ in our SUT experiments, whereas in the experiments presented in Kallio et al. (2009) it was $153.3 \mathrm{~kg} / \mathrm{m}^{3}$ for case 13 and $138.9 \mathrm{~kg} / \mathrm{m}^{3}$ for case 14.

The discrepancies between measured and simulated profiles for all cases were attributed to four main effects. First, the experiments were carried out in a pseudo-2D fluidized bed, with spacing between the walls (i.e., the depth of the bed) of $17 \mathrm{~mm}$. In the previous experiments (Kallio et al., 2009; Shah et al., 2012), the wall spacing was $15 \mathrm{~mm}$. Clearly, wall stresses as well as other 3D effects that are not taken into account in the model affected the flow. The wall stresses usually have positive effects, i.e., enhance the pressure drop. However, this is not consistent with our results, which showed that pressure can be both under- and overestimated. In all cases 1-12, 3D effects are not fully avoided. These effects will be more important for cases with smaller particles (cases 1-4), since small particles have different flow patterns and are often visible on the front and back walls of the riser. The issue of 3D effects will be discussed in more detail in Section 4.4.

The second issue is the fact that as the fluidization process proceeded in the facility, an electric charge built up on the walls of the riser, sticking particles to the walls. To resolve this, an antistatic agent was added to the solids in all our experiments, and the visible effects related to static were removed. It is not known, whether this phenomenon affected the flow. Typically, electrostatic forces acting on particles will reduce the pressure drop, with smaller particles being more susceptible to this effect.

The third issue reflects the fact that the simulations were done with the same mesh for all cases, which was 21 times larger than the smallest particle diameter (particle type 1), but up to 60 times larger than the smallest particles in the mixture (cf. Fig. 2). Therefore, resolution of the clusters will be worse in cases 1-4. The drag reduction related to subgrid-scale clusters was not accounted for in our drag model. Instead, particles were promoted to settling, which redistributed the pressure profile.

Finally, the particle size distribution of the solid phase, which was characterized by a single representative diameter (Sauter mean) in all our simulations, will influence our results. This effect is most important in cases 1-4 and 9-12, which all had broad particle size distributions; it was unlikely for cases 5-8. 
Thus, simulation of cases 5-8 were clearly affected by unresolved clusters and the reduction of the dimensionality, while cases 9-12 also showed effects related to their broad particle size distribution being characterized by a single representative diameter. Because of their small particles, cases 1-4 were affected to a greater extent by all the effects described above.

\subsection{Mesh sensitivity study}

It has been reported in the literature that the mesh independence of fluidized bed simulations is related to the size of the simulated particles (Cloete et al., 2013). For smaller particles, much finer meshes are required to obtain grid independent solutions. Cloete et al. (2013) showed that for large particles of diameter $\sim 0.5 \mathrm{~mm}$, the required mesh resolution was $\sim 20$ times larger than the particle diameter. In contrast, for small particles with diameters $\sim 0.09 \mathrm{~mm}$, mesh independence was not obtained even for mesh sizes only $\sim 3.5$ times larger than the particle diameter.

We carried out mesh independence studies for cases 1,4 ( $d_{32}=281-\mu \mathrm{m}$ particles), and 5 ( $d_{32}=548-\mu \mathrm{m}$ particles) (Table 3). Results of simulations obtained on three different meshes for each case were examined to evaluate the sensitivity of the solution to mesh resolution. Structured meshes with square elements were created in the riser. For smaller particles (cases 1 and 4), the mesh was built out of squares with side lengths of 1.5, 3, and $6 \mathrm{~mm}$. For larger particles (case 5), these side lengths were 3, 6, and $12 \mathrm{~mm}$. This generated meshes with 814,037 (1.5 mm), 203,657 (3 mm), 50,988 (6 mm), and 12,781 (12 mm) elements. Hence, the number of mesh elements is orders of magnitude different for different cases, resulting in considerable differences in computational time. The input data used in all the simulations correspond to the conditions given in Table 3; while settings are those described in Table 4, except for granular temperature, which was calculated using the algebraic equation. We applied the algebraic equation in this time-consuming parametric study to speed up calculations and to make them more stable. As discussed in Section 4.3 below, the results obtained using the algebraic formulation are close enough to those obtained using the partial differential equation to justify this simplification.

In Fig. 7, mean volume fractions and vertical velocities for the solid phase are presented. The mean values do not differ much for different meshes, besides in the regions close to the walls, where a significant drop in solid volume fraction is visible for the fine meshes, which is not reproduced by the coarser meshes. The influence of the particle size on mesh independence can be evaluated by comparing these figures. Changes for largest particles are clearly visible for the 6-mm mesh, while for the finer particles, a 3-mm mesh is required to observe this effect. The significant drop in solid volume fraction near the wall is only partially associated with use of the finer mesh. The algebraic equation used for the granular temperature also contributes to this behavior. This will be discussed in more detail in the next section. 
Fig. 7

In Fig. 8, the mean solid volume fraction (in the center of the riser) and the mean static pressure (on the right wall of the riser) are shown as a function of the vertical distance from the air inlet. The predicted pressure profiles coincide for all meshes in the upper region of the riser. The pressure tends to increase at the bottom, as the mesh decreases. Steep pressure gradients and much higher maximum values of pressure at the bottom of the riser are observed for the coarser meshes. The predicted maximum pressure at the bottom of the riser for the coarse mesh is up to twice that for the fine mesh for case 4. However, the measurement location occurs near the wall, where the downward flowing solids meet inflowing air. Finer resolution of such flow leads to smaller gradients and maximum values. The predicted mean solid volume fractions also coincide well in the upper region of the riser, with maximums occurring approximately $10 \mathrm{~cm}$ above the air inlet. In cases 1 and 4, the predicted maxima of the volume fraction are smallest for the coarsest mesh $(6 \mathrm{~mm})$, and the highest for the medium mesh $(3 \mathrm{~mm})$. For the 1.5-mm mesh, the solids are more evenly distributed, which leads to a smaller volume fraction gradient at the bottom of the riser. Further from the walls, and in the upper region of the riser, averages are comparable for all meshes. Thus, differences become most apparent at the bottom of the riser and close to the walls. The largest differences occur for small particles and high velocities (case 4), which confirms the findings reported in the literature (Cloete et al., 2013).

Fig. 8

\subsection{Effect of applying a partial differential equation for granular temperature}

In the two-fluid model, the solid-phase momentum equation requires closure models for the solid stress tensor. These solid stresses can be modeled using empirical correlations, the KTGF, or a hybrid approach that employs both methods (Cabezas-Gomez et al., 2006). Application of the KTGF allows the user to determine the solid stress. However, it requires solution of the balance equation for granular temperature, which is a measure of particle velocity fluctuations. This balance equation is a complex partial differential equation. Syamlal, Rogers, and O’Brien (1993) simplified this partial differential equation by neglecting diffusion, convection, and unsteady terms; they assumed that only stationary and local dissipation of granular energy needed to be taken into account. According to van Wachem et al. (1998, 2001), these simplifications are valid only for dense regions of flow and at relatively low solid phase velocities. Thus, they are more appropriate for bubbling fluidized beds. Given the complexity of the partial differential equation, longer computational times and instabilities in the solution process, the algebraic form of the equation has been preferred by many authors for simulating bubbling fluidized beds (van Wachem et al., 1998; Cloete et al., 2013; Cloete, Johansen, \& Amini, 2015) as well as risers (Cabezas-Gomez et al., 2006). 
The effect of applying the full partial differential equation for granular temperature is examined in this study for cases 5 and 8 . According to the flow regime diagrams of Bi and Grace (1995), case 5 corresponds to turbulent fluidization ( $\operatorname{Re} / \mathrm{Ar}^{1 / 3}=4.6$ and $A r^{1 / 3}=23.4$ ), while case 8 corresponds to a point slightly above the significant entrainment line $\left(\operatorname{Re} / A r^{1 / 3}=7.8\right.$ and $\left.A r^{1 / 3}=22.5\right)$. In these regimes, the algebraic granular temperature equation should be invalid. The particles in these cases were almost monosized $\left(d_{32}=0.548 \mathrm{~mm}\right)$. In Fig. 9, the mean solid velocities and volume fractions obtained using the partial differential equation (pdegt) and algebraic equation (aegt) are compared. Clearly, the applied algebraic equation reduces the solid fraction near the walls at both test heights. At 1.3-m height above the air inlet, the solid volume fractions obtained using the algebraic equation are higher in the central part of the riser. Likewise, larger differences in the mean solid velocities occur at 1.3-m height. Near the walls, these differences are not as large as for the volume fractions. However, because this effect was not studied for all meshes, it is difficult to predict its behavior for other mesh resolutions. We suspect that the strong drop off in solid volume fraction near the wall shown in Fig. 7 would be smaller, if the full partial differential equation had been used. We conclude that the differences in the predictions are larger in the dilute and fast moving regions, as can be expected, given the important terms that are neglected in the algebraic form of the equation. Thus, applying the simplified granular temperature equation for turbulent fluidization and for dilute-phase transport can lead to incorrect predictions.

Fig. 9

\subsection{D effects}

Given the tremendous computational resources required to perform simulations for 3D geometries, many studies reduce the real system to 2D. To determine the effect of this dimensionality reduction, calculations were carried out for the real 3D geometry of the test facility ( $3 \mathrm{~m}$ high, $0.6 \mathrm{~m}$ wide, and $17 \mathrm{~mm}$ deep) for case 5 , where conditions correspond to turbulent fluidization. In case 5 , the particles were almost monosized $\left(d_{32}=\right.$ $0.548 \mathrm{~mm}$ ); therefore, the different behavior related to small and large particles was absent, allowing us to simply compare the effect of dimensional geometry. The mesh spacing was kept the same in horizontal and vertical directions (as in the 2D studies), while five mesh elements (3.4 mm each) were created to give depth to the riser. All the settings were kept the same as for the 2D cases (cf. Table 4), such that simulations were performed in the same manner. Following the first $10 \mathrm{~s}$ of initial flow in the simulation, data were collected for $20 \mathrm{~s}$ to compute time-averaged values. The mean quantities in 2D and 3D results were compared.

In Fig. 10, the mean pressure on the right wall and mean solid volume fraction in the middle of the riser are shown. Clearly, the maximum pressure at the bottom of the riser is almost $1.92 \mathrm{kPa}$ higher in 2D than in 3D. Near the bottom of the riser, the pressure obtained in 2D decreases more rapidly as a function of height. In both the 2D and 3D models, the pressure is higher than experimental values until $1.7 \mathrm{~m}$ in height. However, the distribution obtained for the 3D case is more aligned with the experimental data in the upper regions, and at the 
very bottom of the riser, with only slight over-predictions to the measured values from 0.2 to $0.8 \mathrm{~m}$. The pressure distribution is obviously a result of the distribution of solids in the riser. It can be seen from Fig. 10 (right), that the expansion of the turbulent bed is lower for the 3D model. In Fig. 11, the solid volume fraction and vertical velocities at $0.25 \mathrm{~m}$ and $1.3 \mathrm{~m}$ above the air inlet are shown. The differences in mean quantities in the 2D and 3D models are substantial. The solid velocities are much lower for the 3D model in the center of the riser at both test heights. Similarly, at the side walls, the downward flow velocity is lower in the 3D simulation. In Fig. 12(a), contours of mean pressure for the 2D and 3D geometry are presented. There is a significant difference in the pressure distributions near the walls at the bottom of the riser. The pressure is much higher for the 2D model in this region. In the 3D model, the pressure is much more evenly distributed in the horizontal direction. In the upper region of the riser, the isobars are virtually horizontal in both cases. In Fig. 12(b), contours of mean solid volume fraction are presented. Here, in the 2D model, the bed is more expanded. Lower volume fractions are observed in the middle of the riser. According to Fig. 11, the streams of downward flowing solids near the walls are narrower in the 2D model, reaching to the very bottom of the riser. Simultaneously, the downward flow velocity is higher. This gives rise to the high pressures shown in Fig. 12(a) near the walls. Although there are only five mesh elements along the depth of the riser, considerable differences between the instantaneous flow fields are observed in this direction. In Fig. 13, instantaneous solid volume fraction and vertical component of solid velocity distributions are presented. The fields are displayed in planes created at the centers of first cells, $0.0017 \mathrm{~m}$ from the walls (left and right pictures in the figures) as well as in the center of the riser (middle picture in the figure). There is a substantial difference in the solid velocity fields in these three planes, which is associated with the slightly different solid volume fractions for the three images shown in Fig. 13(a). In the center plane, the solid volume fractions are clearly lower in the central region. As a consequence, solid velocity is higher in this region.

Figs. 10-13

\section{Conclusions}

Both experimental investigations and numerical simulations of a pseudo-2D riser are presented here. Experiments were performed for various air flow rates, particle types/diameters, and particle size distributions. Pressure distributions along the wall of the riser were measured to compare with simulation results obtained using an Euler-Euler approach. Qualitative comparison showed that the trends of simulated pressure distributions are the same as those observed in measured data. Generally, pressure was well predicted in all cases, just above the air inlet at a height of $0.1 \mathrm{~m}$. Simulations over-predicted pressure in most regions at higher elevations. This behavior was slightly different for the smallest particles with broad particle size distribution, where pressures were over-predicted at the bottom of the riser and under-predicted in the upper regions. This is attributed to 3D effects and to drag reduction related to a significant amount of unresolved clusters that are 
especially important for smaller particles. The higher pressures in simulations were attributed to reduced dimensionality in the 2D model. To verify the correctness of the applied computational strategy and selection of the models, we performed additional calculations and compared the results with simulation and experimental data from the literature (Kallio et al., 2009; Shah et al., 2012). In these instances, the solid volume fractions coincided well with measured data.

A mesh sensitivity study was conducted to determine dependence of the results on mesh density. A relatively high dependence on mesh elements was observed near the walls, which is partially attributed to the mesh resolution and partially to the algebraic equation that was applied to simplify the granular temperature calculation in the mesh sensitivity study. Comparison of results obtained using the partial differential equation and the algebraic equation confirm this observation. Hence, use of the algebraic equation has a clear impact on the predicted solid volume fractions and velocity. Thus, if possible, the full partial differential equation should be used for turbulent fluidization and dilute-phase transport regimes. The impact of simplifying the granular temperature equation needs to be evaluated in more detail.

Effects of the dimensionality reduction (i.e., a 3D geometry represented by a 2D model) also were examined. Here, a simulation with the real 3D geometry was performed for case 5, with particles characterized by a narrow size distribution. The pressure along the right wall in the 3D model was generally lower than that for the 2D model, except in the lower part of the riser. Our results also showed that the pressure substantially increases in the corners of the 2D geometry, giving rise to a steep pressure gradient along the right wall, at the bottom of the riser. Comparison of the results obtained in 2D and 3D simulations has also shown that a reduction of the dimensionality can lead to substantial differences in mean solid distribution and velocities. We conclude that 3D simulations are preferable, providing better accuracy. Thus, for comparisons commonly done to validate submodels, 3D simulations should be carried out. However, 2D simulations produce reasonable qualitative results and are useful for parametric studies, where unnecessarily long simulations must be avoided.

\section{Acknowledgements}

Adam Klimanek was supported by the BK-M grant No. BK-369/RIE-6/2011. This research was supported by the National Center for Research and Development, as part of the development of coal gasification technology for high production of fuels and energy (CzTB. 5.2). In addition, we received support from the National Centre for Research and Development, within the confines of the Research and Development Strategic Program Advanced Technologies for Energy Generation project No. 2 Oxy-combustion technology for PC and FBC boilers with $\mathrm{CO}_{2}$ capture (Agreement No. SP/E/2/66420/10). 


\section{References}

Almuttahar, A., \& Taghipour, F. (2008a). Computational fluid dynamics of a circulating fluidized bed under various fluidization conditions. Chemical Engineering Science, 63, 1696-1709.

Almuttahar, A., \& Taghipour, F. (2008b). Computational fluid dynamics of high density circulating fluidized bed riser: Study of modeling parameters. Powder Technology, 185, 11-23.

ANSYS Inc. (2011). ANSYS FLUENT 14.0 documentation. ANSYS, Inc. Software documentation.

Benyahia, S., Arastoopour, H., Knowlton, T.M., \& Massah, H. (2000). Simulation of particles and gas flow behavior in the riser section of a circulatingfluidized bed using the kinetic theory approach for the particulate phase. Powder Technology, 112, 24-33.

Bi, H.T., \& Grace, J.R. (1995). Flow regime diagrams for gas-solid fluidization and upward transport. International Journal of Multiphase Flow, 21, 1229-1236.

Cabezas-Gomez, L., Silva, R.C., \& Milioli, F.E. (2006). Some modeling and numerical aspects of the twofluid simulation of the gas-solids flow in a CFB riser. Brazilian Journal of Chemical Engineering, 23, 487-496.

Chalermsinsuwan, B., Piumsomboon, P., \& Gidaspow, D. (2009a). Kinetic theory based computation of PSRI riser: Part I-Estimate of mass transfer coefficient. Chemical Engineering Science, 64, 1195-1211.

Chalermsinsuwan, B., Piumsomboon, P., \& Gidaspow, D. (2009b). Kinetic theory based computation of PSRI riser: Part II-Computation of mass transfer coefficient with chemical reaction. Chemical Engineering Science, 64, 1212-1222.

Cloete, S., Amini, S., \& Johansen, S.T. (2011). A fine resolution parametric study on the numerical simulation of gas-solid flows in a periodic riser section. Powder Technology, 205, 103-111.

Cloete, S., Johansen, S.T., \& Amini, S. (2015). Grid independence behavior of fluidized bed reactor simulations using the two fluid model: Effect of particle size. Powder Technology, 269, 153-165.

Cloete, S., Zaabout, A., Johansen, S.T., van Sint Annaland, M., Gallucci, F., \& Amini, S. (2013). The generality of the standard 2D TFM approach in predicting bubbling fluidized bed hydrodynamics. Powder Technology, 235, 735-746. 
Dullien, F.A. (1992). Porous media: Fluid transport and pore structure (2 ${ }^{\text {nd }}$ ed.). San Diego: Academic Press.

Gidaspow, D. (1994). Multiphase flow and fluidization: Continuum and kinetic theory descriptions. Boston: Academic Press.

Gidaspow, D., Bezburuah, R., \& Ding, J. (1992). Hydrodynamics of circulating fluidized beds, kinetic theory approach. In Fluidization VII, Proceedings of the 7th Engineering Foundation Conference on Fluidization (pp. 75-82).

Hartge, E., Ratschow, L., Wischnewski, R., \& Werther, J. (2009). CFD-simulation of a circulating fluidized bed riser. Particuology, 7, 283-296.

Huilin, L., Gidaspow, D., Bouillard, J., \& Wentie, L. (2003). Hydrodynamic simulation of gas-solid flow in a riser using kinetic theory of granular flow. Chemical Engineering Journal, 95, 1-13.

Johnson, P.C., \& Jackson, R. (1987). Frictional-collisional constitutive relations for granular materials, with application to plane shearing. Journal of Fluid Mechanics, 176, 67-93.

Kallio, S., Airaksinen, J., Gulden, M., Hermanson, A., Peltola, J., \& Ritvanen, J., et al. (2009). Experimental and numerical study of hydrodynamics in a circulating fluidized bed. In Proceedings of Finnish-Swedish Flame Days, Electronic version.

Kallio, S., Peltola, J., \& Niemi, T. (2014). Modeling of the time-averaged gas-solid drag force in a fluidized bed based on results from transient 2D Eulerian-Eulerian simulations. Powder Technology, 261, 257-271.

Lu, H., Wang, S., He, Y., Ding, J., Liu, G., \& Hao, Z. (2008). Numerical simulation of flow behavior of particles and clusters in riser using two granular temperatures. Powder Technology, 182, 282-293.

Lun, C.K.K., Savage, S.B., Jeffrey, D.J., \& Chepurniy, N. (1984). Kinetic theories for granular flow: Inelastic particles in Couette flow and slightly inelastic particles in a general flow field. Journal of Fluid Mechanics, 140, 223-256.

Myöhänen, K., \& Hyppänen, T. (2011). A three-dimensional model frame for modelling combustion and gasification in circulating fluidized bed furnaces. International Journal of Chemical Reactor Engineering, 9, A25, doi: 10.1515/1542-6580.2571.

Schaeffer, D.G. (1987). Instability in the evolution equations describing incompressible granular flow. Journal of Differential Equations, 66, 19-55. 
Shah, S., Ritvanen, J., Hyppänen, T., \& Kallio, S. (2012). Space averaging on a gas-solid drag model for numerical simulations of a CFB riser. Powder Technology, 218, 131-139.

Syamlal, M., \& O’Brien, T.J. (1989). Computer simulation of bubbles in a fluidized bed. AIChE Symposium Series, 85, 22-31.

Syamlal, M., Rogers, W., \& O’Brien, T.J. (1993). MFIX documentation: Theory guide. National Energy Technology Laboratory, Department of Energy, Technical Note DOE/METC-95/1013 and NTIS/DE95000031.

van Wachem, B.G.M., Schouten, J.C., Krishna, R., \& van den Bleek, C.M. (1998). Eulerian simulations of bubbling behavior in gas-solid fluidized beds. Computers \& Chemical Engineering, 22, S299-S306.

van Wachem, B.G.M., Schouten, J.C., van den Bleek, C.M., Krishna, R., \& Sinclair, J.L. (2001). Comparative analysis of CFD models of dense gas-solid systems. AIChE Journal, 47, 1035-1051.

Wang, X., Jiang, F., Xu, X., Fan, B., Lei, J., \& Xiao, Y. (2010). Experiment and CFD simulation of gas solid flow in the riser of dense fluidized bed at high gas velocity. Powder Technology, 199, 203-212.

Wischnewski, R., Ratschow, L., Hartge, E., \& Werther, J. (2010). Reactive gas-solids flows in large volumes 3D modeling of industrial circulating fluidized bed combustors. Particuology, 8, 67-77.

Xie, N., Battaglia, F., \& Pannala, S. (2008). Effects of using two- versus three-dimensional computational modeling of fluidized beds Part I, hydrodynamics. Powder Technology, 182, 1-13.

Zhang, N., Lu, B., Wang, W., \& Li, J. (2008). Virtual experimentation through 3D full-loop simulation of a circulating fluidized bed. Particuology, 6, 529-539.

Zhang, N., Lu, B., Wang, W., \& Li, J. (2010). 3D CFD simulation of hydrodynamics of a 150 MWe circulating fluidized bed boiler. Chemical Engineering Journal, 162, 821-828. 


\section{Figure captions:}

Fig. 1. Circulating fluidized bed at the Silesian University of Technology.

Fig. 2. Particle size distributions of type 1 (left) and type 2 (right) particles obtained from sieve analysis.

Fig. 3. Schematic showing the 2D geometry used for the numerical simulations.

Fig. 4. Simulated axial distributions of the mean pressure along the right wall of the riser and mean solid volume fraction in the middle of the riser for (a) cases 1-4 (c1-c4), (b) cases 5-8 (c5-c8), and (c) cases 9-12 (c9-c12) compared with the corresponding experimental results.

Fig. 5. Pressure distribution along the right wall of the riser obtained for case 13 (c13, left) and 14 (c14, right) compared with data from Kallio et al. (2009).

Fig. 6. Comparison of the calculated and measured lateral solid volume fraction distributions (Kallio et al., 2009) with the simulated results for (a) case 13 at $0.2 \mathrm{~m}$ (left) and $1.3 \mathrm{~m}$ (right) and (b) case 14 at $0.2 \mathrm{~m}$ (left) and $1.3 \mathrm{~m}$ (right) above the air inlet.

Fig.7. Simulated lateral distributions of mean solid volume fraction (right) and vertical velocity (left) at the heights of $0.25 \mathrm{~m}$ and $1.3 \mathrm{~m}$ above the air distributor for (a) three mesh sizes (1.5, 3, and $6 \mathrm{~mm}$ ) for case 1 , (b) three mesh sizes $(1.5,3$, and $6 \mathrm{~mm})$ for case 4 , and (c) three mesh sizes $(3,6$, and $12 \mathrm{~mm})$ for case 5 .

Fig. 8. Simulated axial distributions of mean solid volume fraction (in the center of the riser) and static pressure (on the right wall of the riser) for (a) three mesh sizes $(1.5,3$, and $6 \mathrm{~mm}$ ) for case 1 , (b) three mesh sizes $(1.5,3$, and $6 \mathrm{~mm}$ ) for case 4 , and (c) three mesh sizes $(3,6$, and $12 \mathrm{~mm})$ for case 5 .

Fig. 9. Simulated lateral distributions of mean solid velocities (left) and volume fractions (right) at $0.25 \mathrm{~m}$ and $1.3 \mathrm{~m}$ heights above the air distributor for cases 5 and 8 obtained using a 6-mm mesh, with the granular temperature solved using either a partial differential equation (pdegt) or algebraic equation (aegt).

Fig. 10. Comparison of the axial distributions of mean pressure along the right wall of the riser (left) and mean solid volume fraction in the middle of the riser (right) for both 2D and 3D simulations (case 5). 
Fig. 11. Comparison of the lateral distributions of mean solid volume fractions (left) and mean solid vertical velocities (right) for 2D and 3D simulations at 0.25 - and $1.3-\mathrm{m}$ heights above the air inlet (case 5).

Fig. 12. Comparisons of contours of (a) mean static pressure and (b) mean solid volume fraction for 2D (left) and 3D (right) geometry (case 5). The regions in (b) where solid volume fractions are lower than $10^{-10}$ are shown in white.

Fig. 13. Comparisons of (a) instantaneous solid volume fraction distributions and (b) instantaneous vertical solid velocity distributions for the 3D geometry near the front wall (left), in the center (middle), and near the back wall (right) of the riser (case 5). The regions in (a) where volume fractions are lower than $10^{-8}$ are shown in white. 


\section{Tables:}

Table 1 Properties of the three fluidized materials

\begin{tabular}{|l|c|c|c|}
\hline Particle type & 1 & 2 & 3 \\
\hline Sauter mean diameter $(\mu \mathrm{m})$ & 281 & 548 & 1000 \\
\hline Density $\left(\mathrm{kg} / \mathrm{m}^{3}\right)$ & 2478 & 2478 & 2500 \\
\hline Packing limit & 0.62 & 0.62 & 0.63 \\
\hline
\end{tabular}

Table 2 Diameters and terminal velocities (at $T=298 \mathrm{~K}$ and $p=1 \mathrm{~atm}$ ) of the particles used in the experiments

\begin{tabular}{|l|c|c|c|}
\hline \multicolumn{1}{|c|}{ Experiment } & 1 & 2 & 3 \\
\hline Sauter mean diameter, $d_{32}(\mu \mathrm{m})$ & 281 & 548 & 708 \\
\hline Min. diameter, $d_{\min }(\mu \mathrm{m})$ & 150 & 157 & 157 \\
\hline Max. diameter, $d_{\max }(\mu \mathrm{m})$ & 565 & 670 & 1000 \\
\hline Terminal velocity for $d_{32}(\mathrm{~m} / \mathrm{s})$ & 2.11 & 4.08 & 5.19 \\
\hline Terminal velocity for $d_{\min }(\mathrm{m} / \mathrm{s})$ & 1.00 & 1.05 & 1.05 \\
\hline Terminal velocity for $d_{\max }(\mathrm{m} / \mathrm{s})$ & 4.20 & 4.93 & 6.97 \\
\hline
\end{tabular}


Table 3 Operating conditions of the three fluidized materials in different experiments

\begin{tabular}{|c|c|c|c|}
\hline Case No. & Fluidization velocity $(\mathrm{m} / \mathrm{s})$ & Air density $\left(\mathrm{kg} / \mathrm{m}^{3}\right)$ & Air mass flow rate $(\mathrm{kg} / \mathrm{s})$ \\
\hline \multicolumn{4}{|c|}{ Experiment 1, ambient pressure $99.8 \mathrm{kPa}$} \\
\hline 1 & 1.61 & 1.21 & 0.0198 \\
\hline 2 & 2.34 & 1.19 & 0.0285 \\
\hline 3 & 2.65 & 1.18 & 0.0318 \\
\hline 4 & 3.20 & 1.16 & 0.0379 \\
\hline \multicolumn{4}{|c|}{ Experiment 2, ambient pressure $101.2 \mathrm{kPa}$} \\
\hline 5 & 3.29 & 1.14 & 0.0381 \\
\hline 6 & 3.93 & 1.14 & 0.0456 \\
\hline 7 & 4.70 & 1.14 & 0.0545 \\
\hline 8 & 5.77 & 1.09 & 0.0641 \\
\hline \multicolumn{4}{|c|}{ Experiment 3, ambient pressure $100.4 \mathrm{kPa}$} \\
\hline 9 & 3.30 & 1.20 & 0.0404 \\
\hline 10 & 4.02 & 1.17 & 0.0479 \\
\hline 11 & 4.82 & 1.13 & 0.0557 \\
\hline 12 & 5.67 & 1.10 & 0.0638 \\
\hline
\end{tabular}


Table 4 Closure models and parameters used in the simulations

\begin{tabular}{|l|l|}
\hline Granular viscosity & according to Gidaspow et al. (1992) \\
\hline Granular bulk viscosity & according to Lun et al. (1984) \\
\hline Frictional viscosity & according to Schaeffer (1987) \\
\hline Angle of internal friction & $30^{\circ}$ \\
\hline Frictional pressure & based on KTGF (ANSYS Inc., 2011) \\
\hline Frictional modulus & derived from ANSYS Inc. (2011) \\
\hline Friction packing limit & 0.6 \\
\hline Granular temperature & Partial differential equation \\
\hline Granular conductivity & according to Gidaspow et al. (1992) \\
\hline Solids pressure & according to Lun et al. (1984) \\
\hline Radial distribution & according to Lun et al. (1984) \\
\hline Elasticity modulus & derived from ANSYS Inc. (2011) \\
\hline Packing limit & 0.62 \\
\hline Drag model & according to Huilin et al. (2003) \\
\hline Restitution coefficient & 0.9 \\
\hline Wall boundary condition & according to Johnson \& Jackson (1987) \\
\hline Wall restitution coefficient & 0.2 \\
\hline Wall specularity coefficient & 0.01 \\
\hline Turbulence model & standard $k-\varepsilon$ (dispersed) (ANSYS Inc., 2011) \\
\hline
\end{tabular}


Figure 1

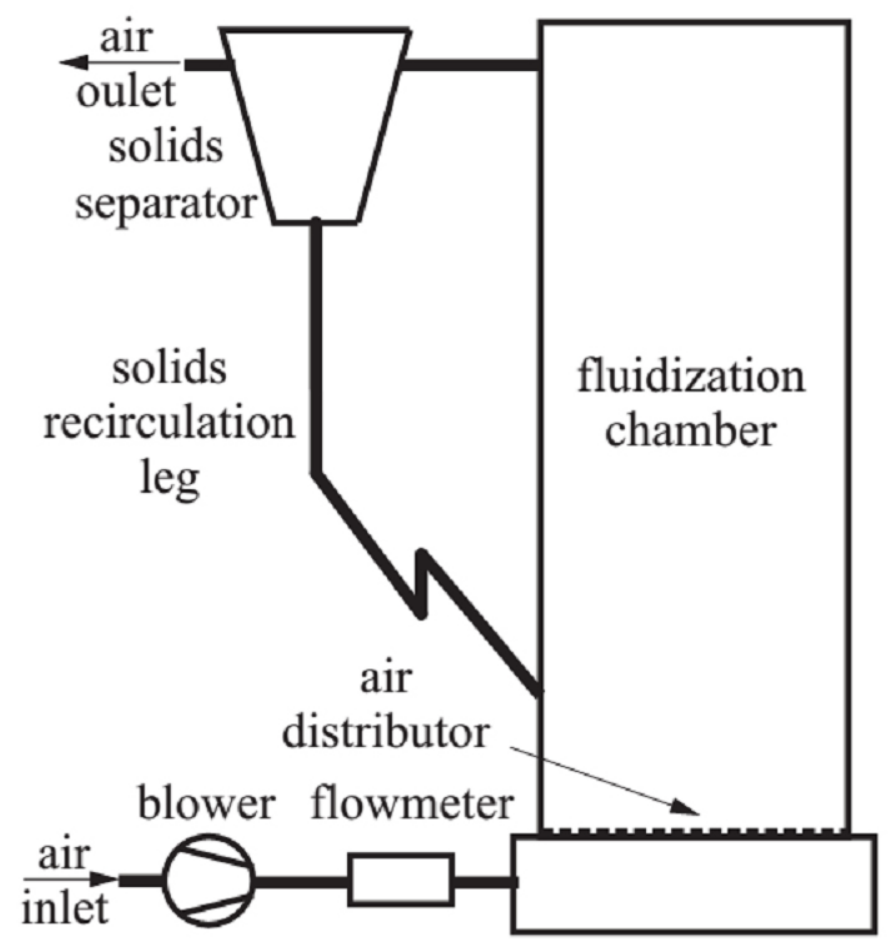


Figure 2
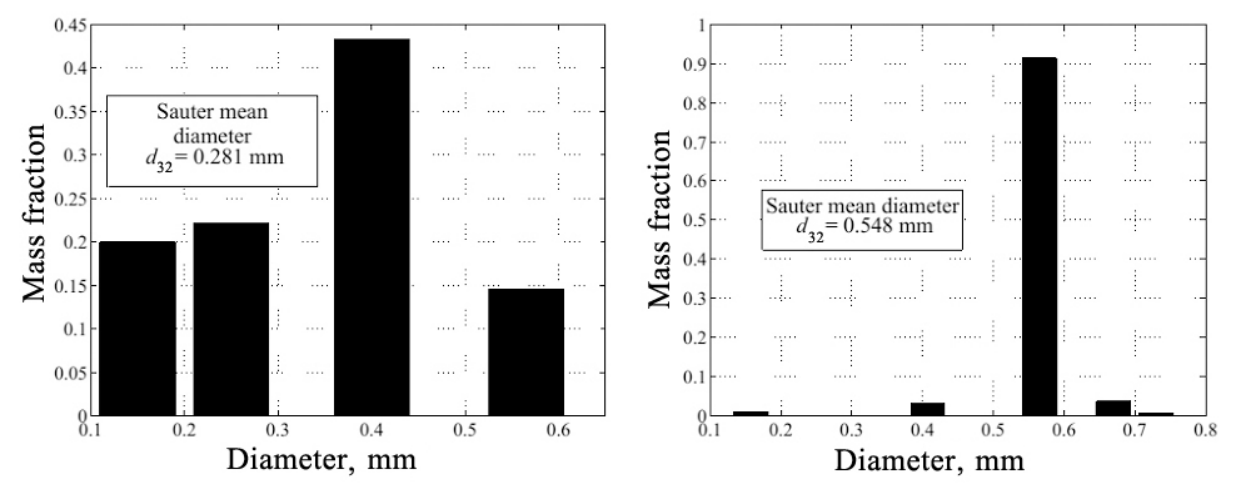
Figure 3

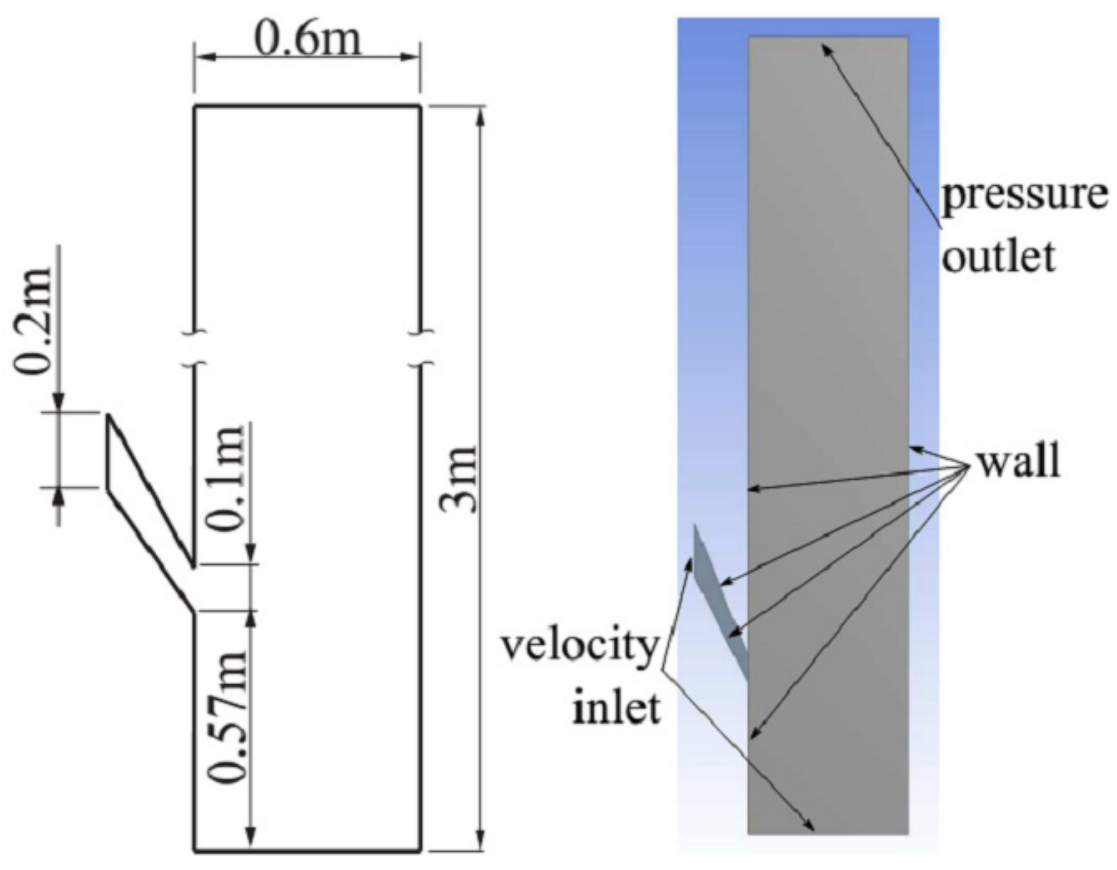


Figure 4
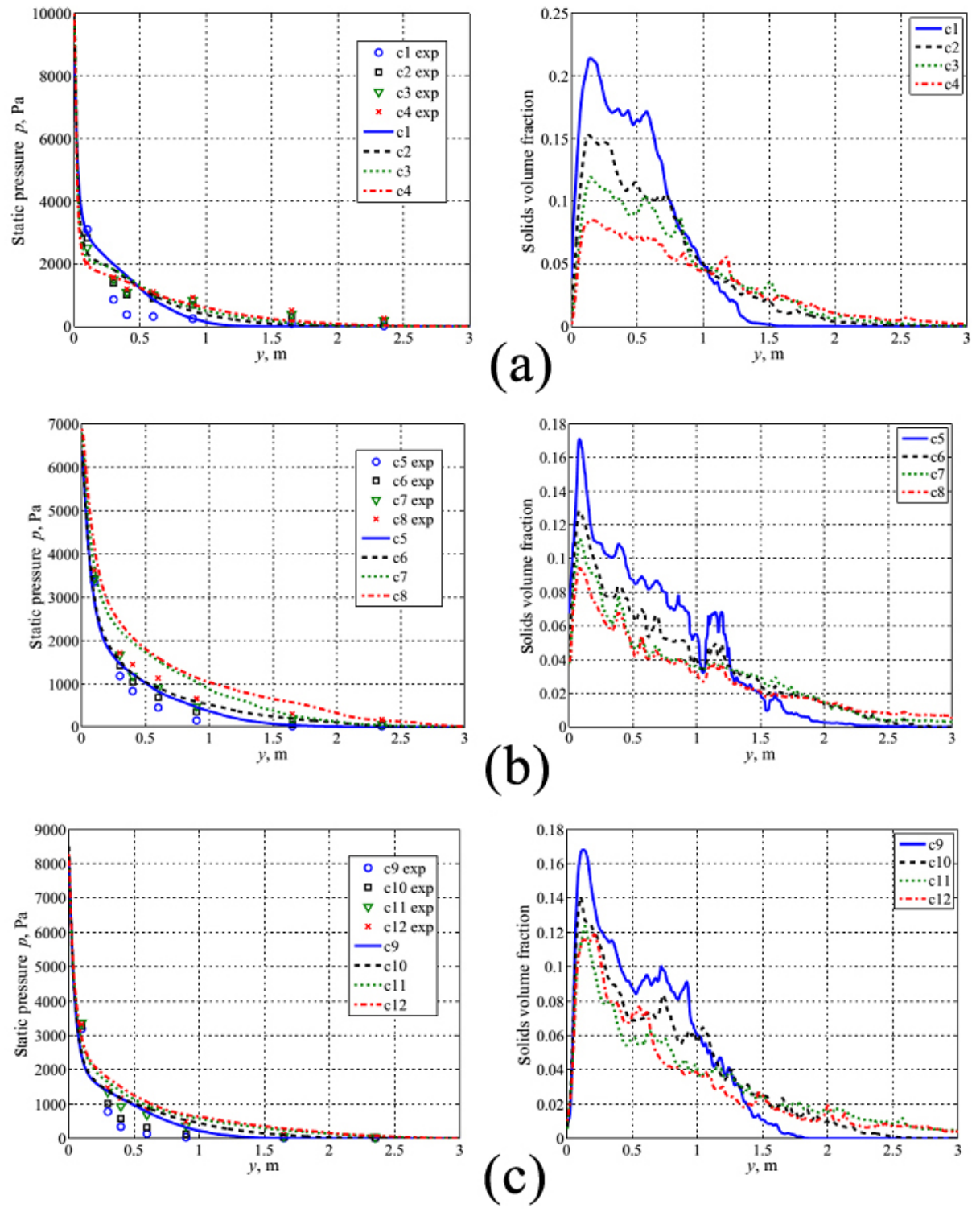
Figure 5
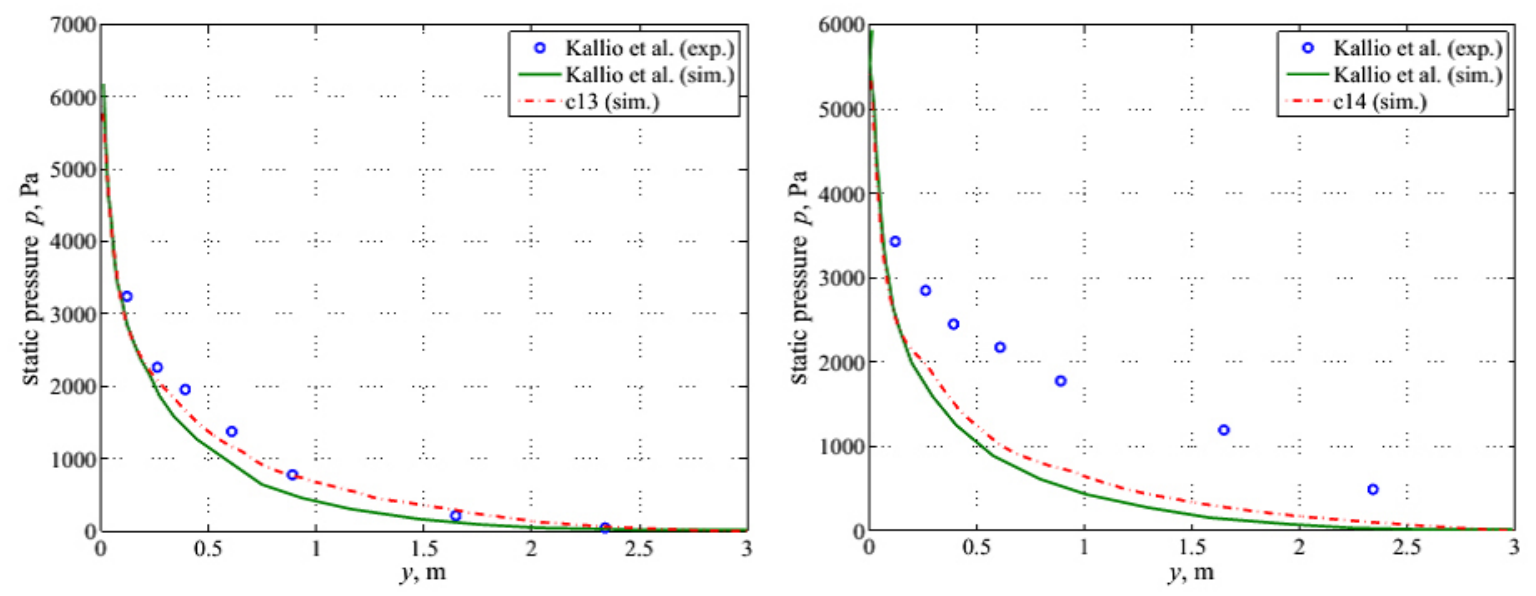
Figure 6
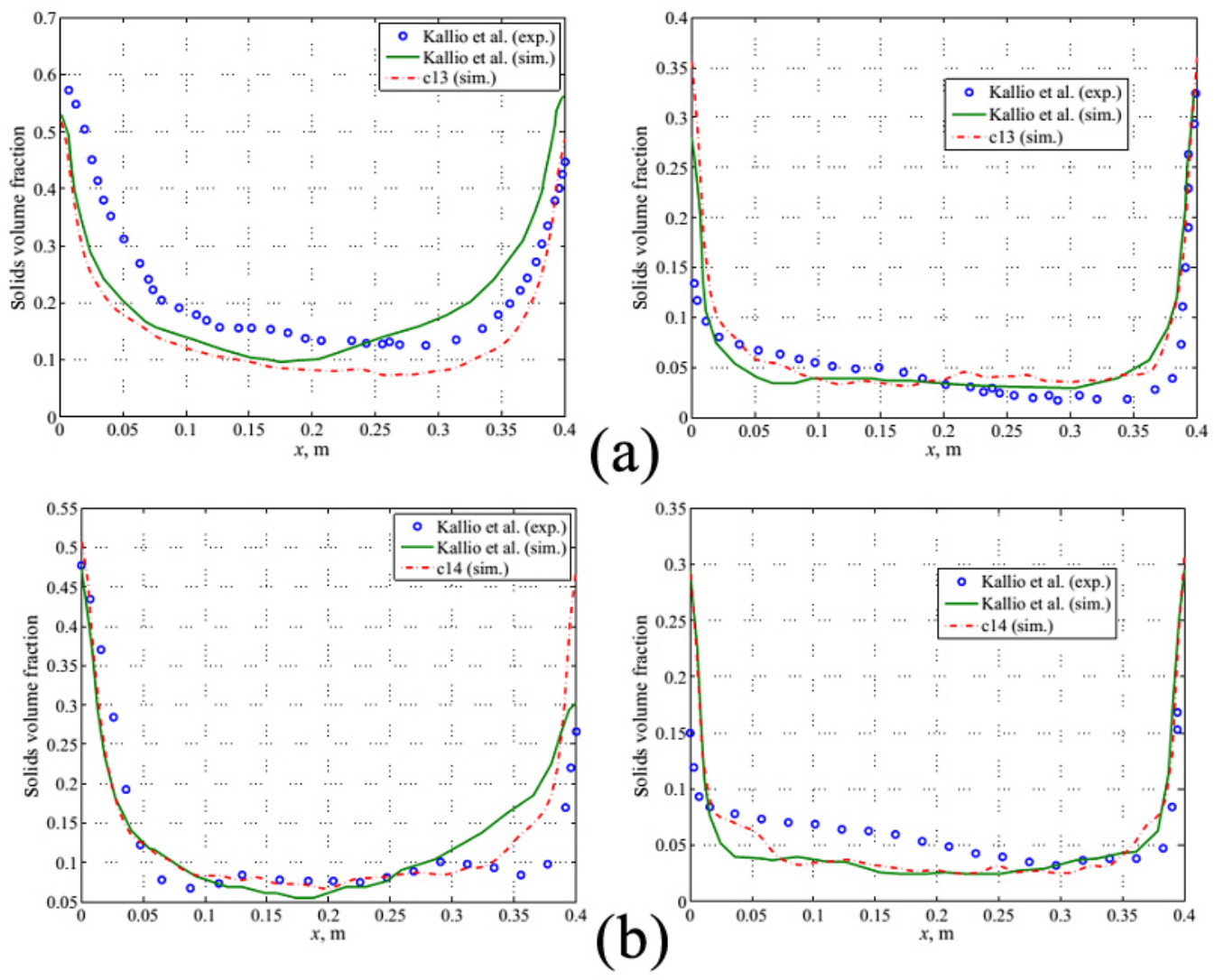


\section{Figure 7}
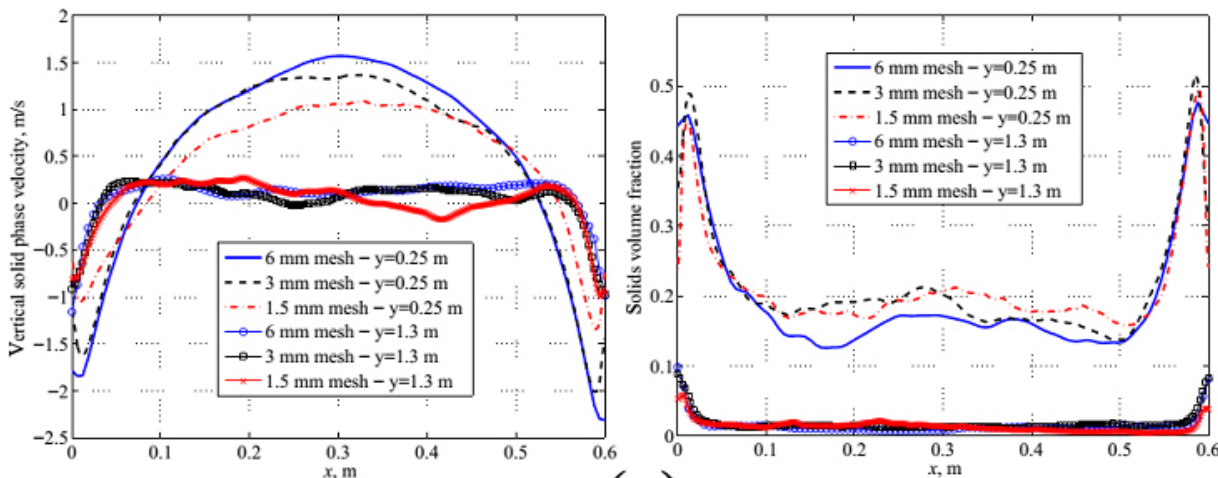

(a)
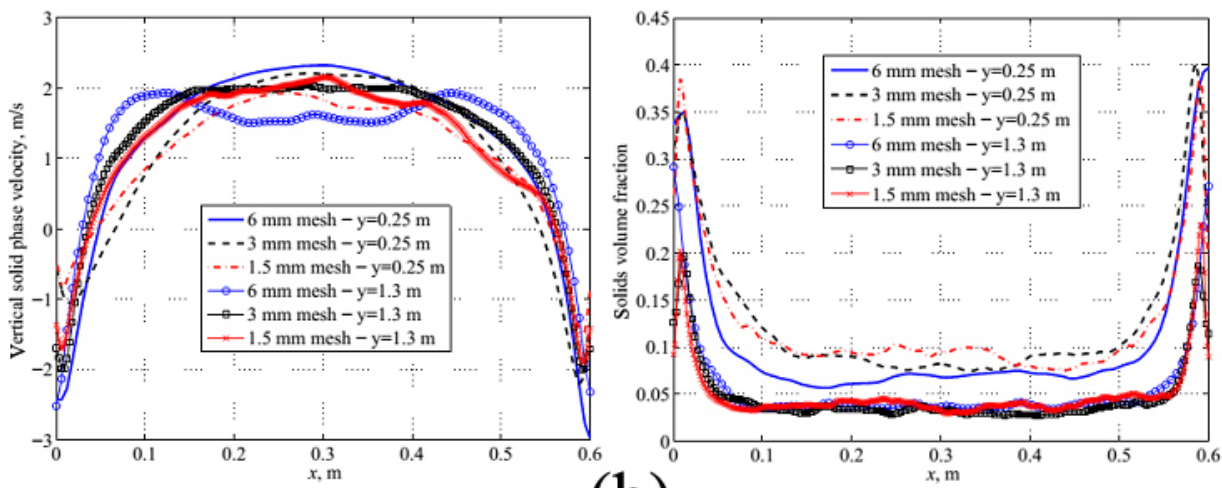

(b)
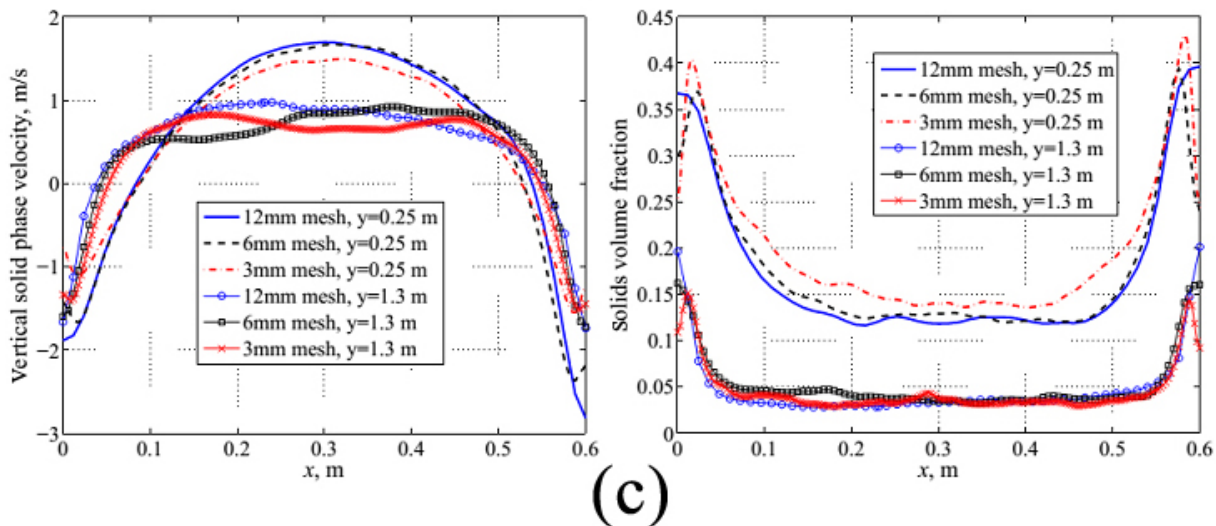
Figure 8
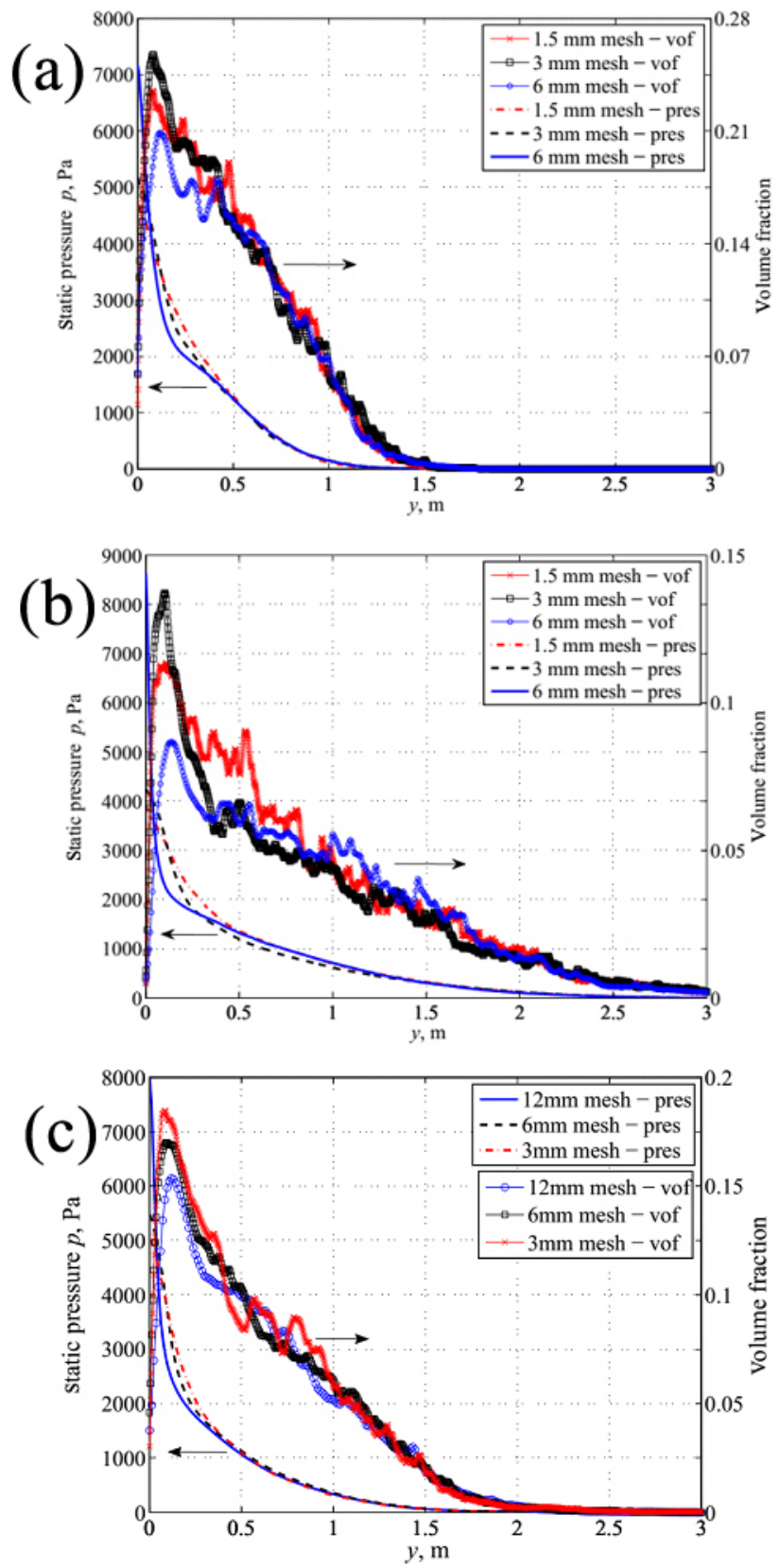
Figure 9
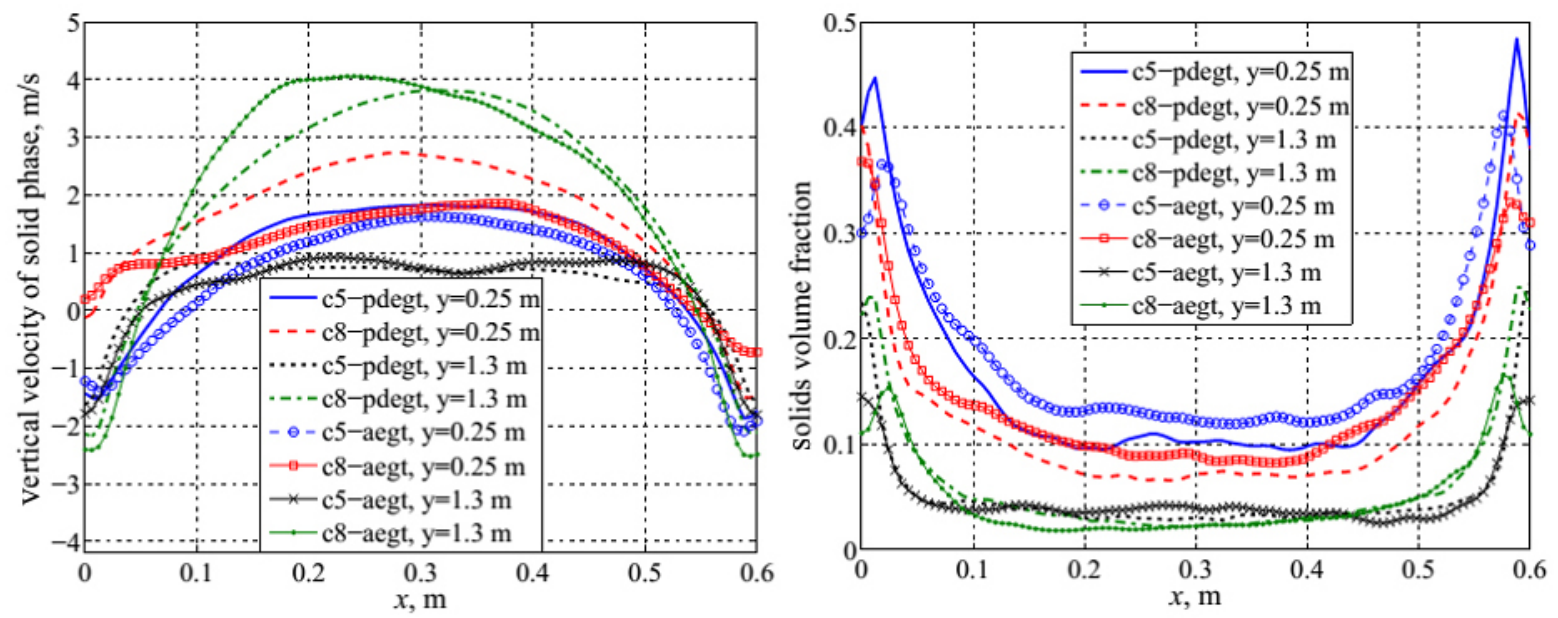
Figure 10
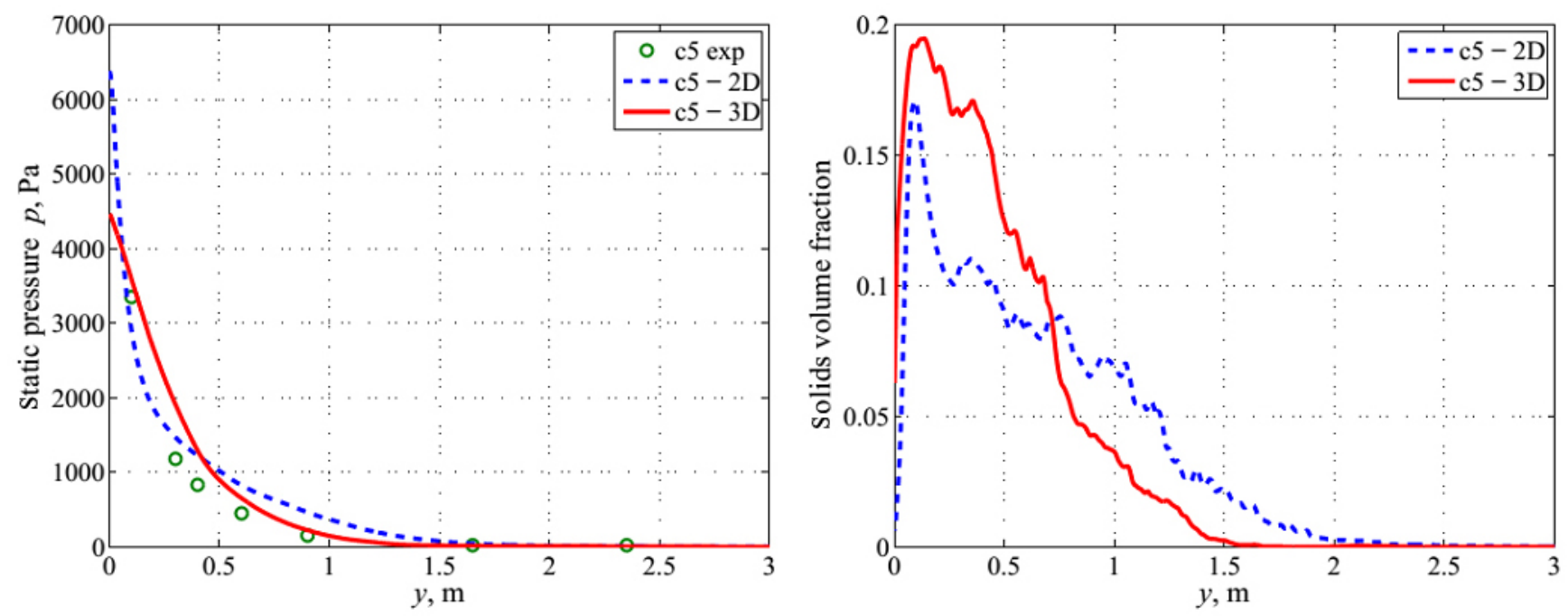
Figure 11
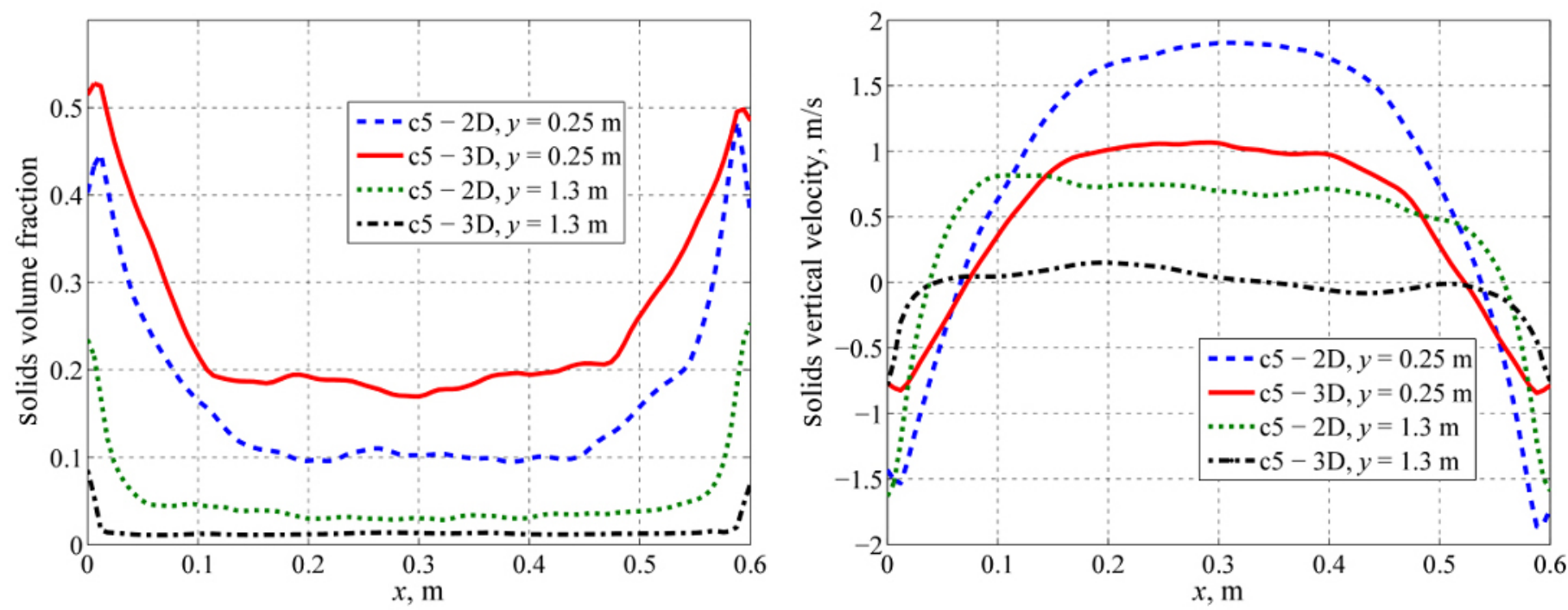
Figure 12
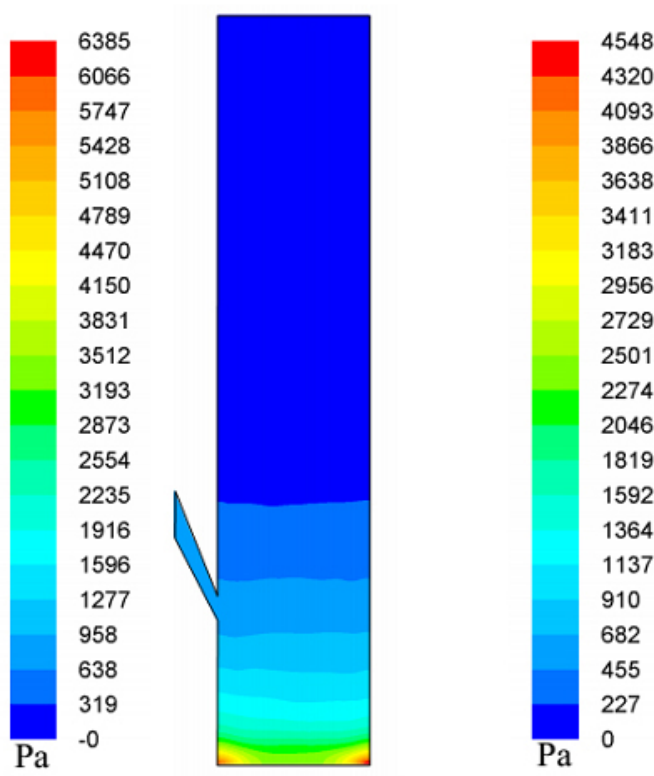

3866

3638

3411

3183

2956

2729

2501

2274

2046

1819

1592

1364

1137

910

682

455

$\mathrm{Pa}^{227}$

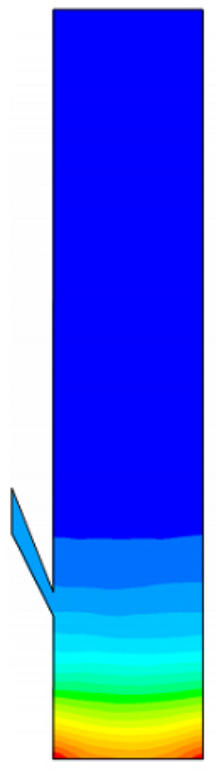

(a)
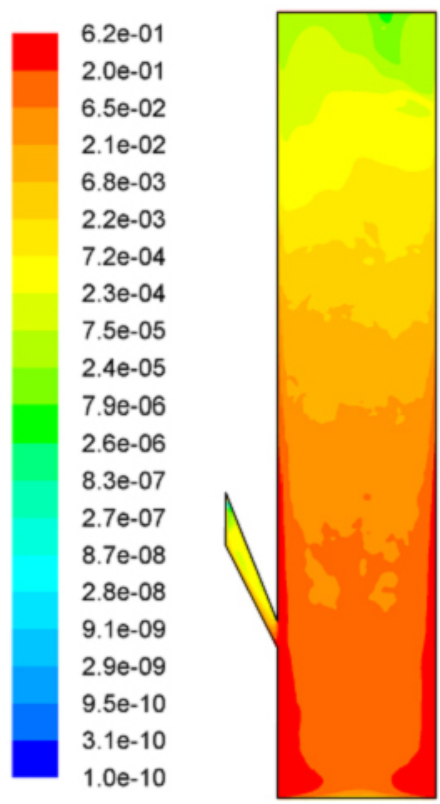

$6.2 \mathrm{e}-01$
$2.0 \mathrm{e}-01$
$6.5 \mathrm{e}-02$

$6.5 \mathrm{e}-02$
$2.1 \mathrm{e}-02$

6.8e-03

2.2e-03

7.2e-04

2.3e-04

7.5e-05

2.4e-05

7.9e-06

2.6e-06

8.3e- 07

2.7e-07

8.7e-08

$2.8 \mathrm{e}-08$

9.1e-09

2.9e-09

9.5e-10

$3.1 \mathrm{e}-10$

$1.0 \mathrm{e}-10$

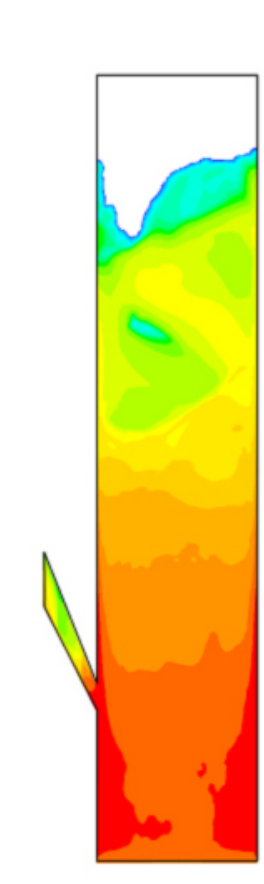

(b) 
Figure 13
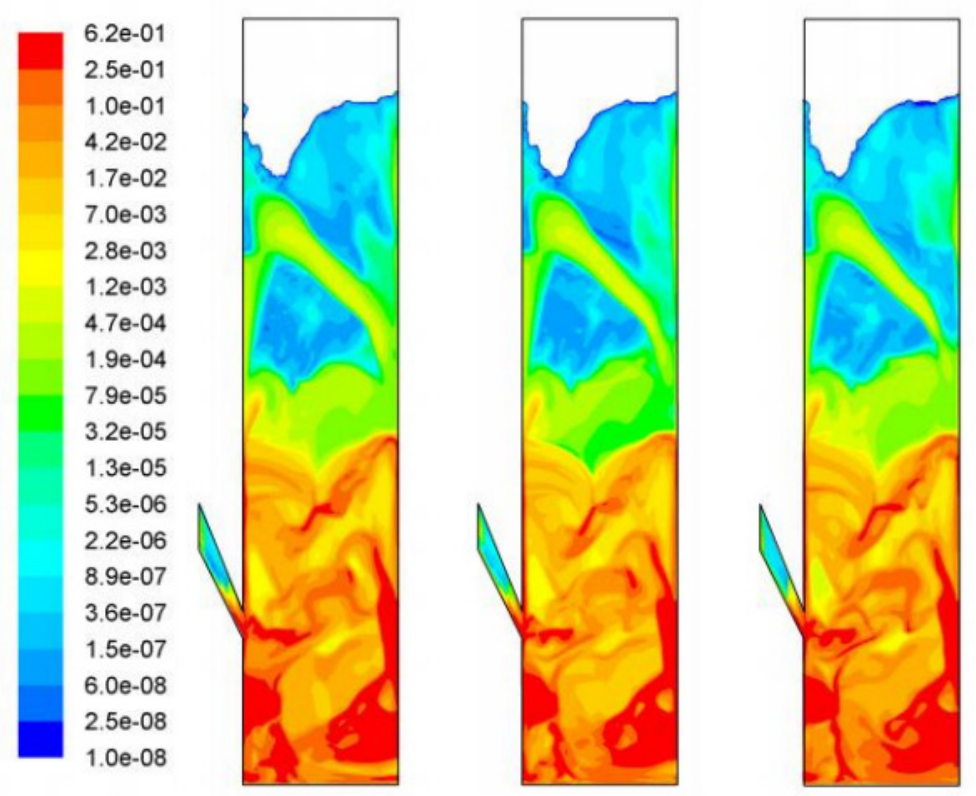

(a)
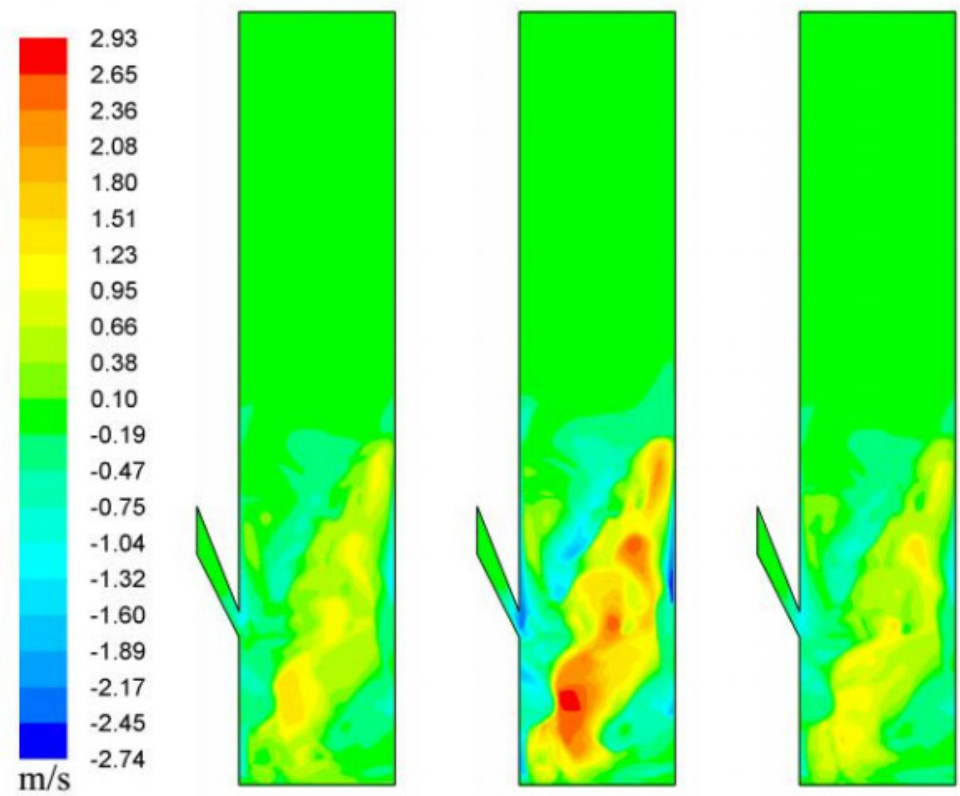

(b) 
Graphical Abstract
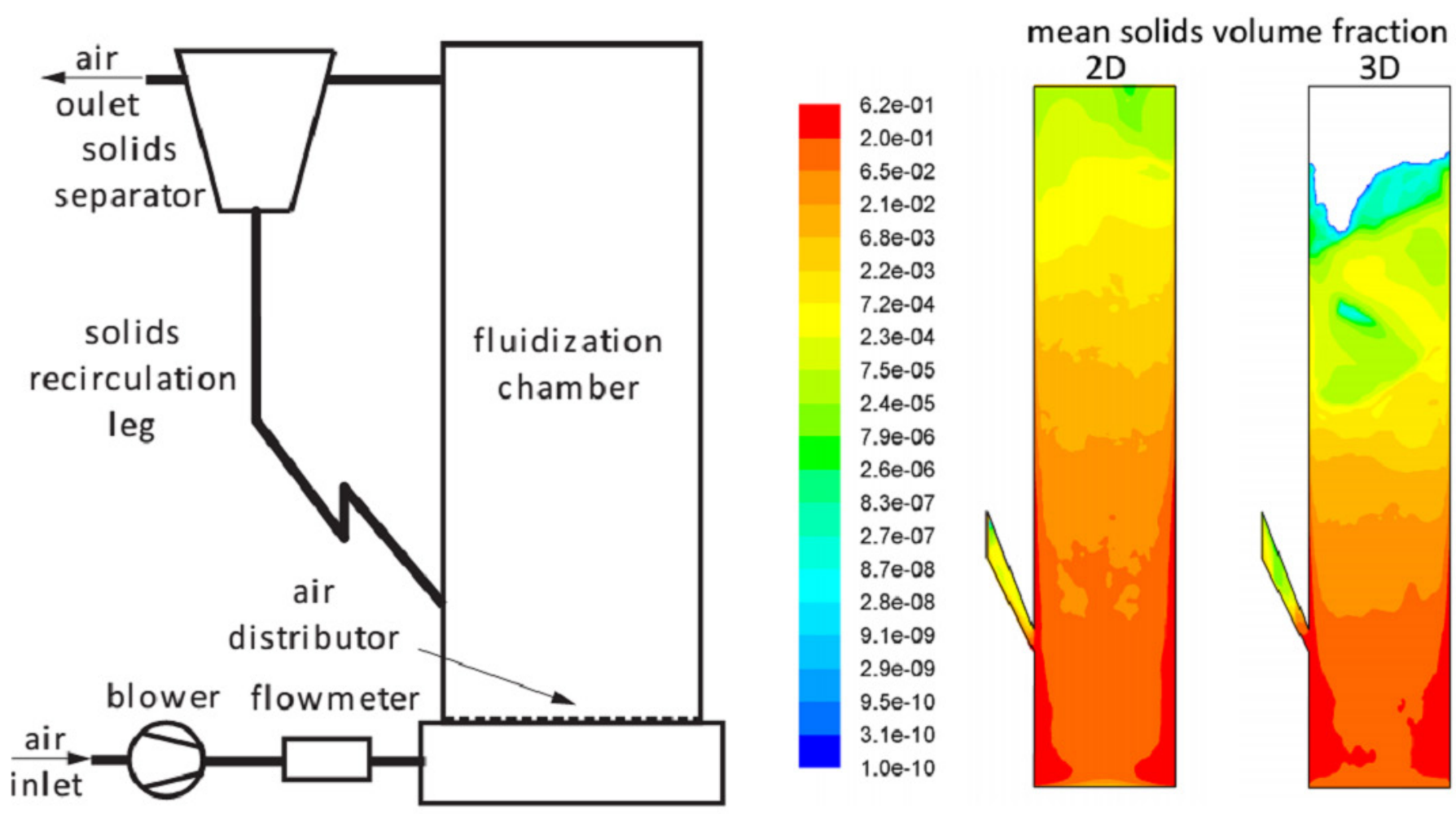